\title{
重庆市盐井沟第四纪哺乳动物化石经典产地的 新发现与时代解释
}

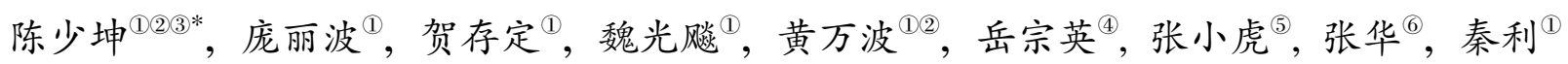

(1) 重庆三峡古人类研究所, 重庆中国三峡博物馆, 重庆 400015;

(2) 中国科学院古脊椎动物与古人类研究所, 北京 100044;

(3) 中国科学院大学, 北京 100049;

(4) 万州区博物馆, 万州 404000 ;

(5) 河南省文物考古研究所, 郑州 450000;

(6) 常州博物馆, 常州 213022

* 联系人, E-mail: cskcsk2000@163.com

2012-12-25 收稿, 2013-03-22 接受, 2013-06-08 网络版发表

国家重点基础研究发展计划(2012CB821906)、国家自然科学基金(40730210)和中国科学院知识创新工程重要方向项目(KL210207)资助

摘要 重庆市万州区盐井沟是我国最早被报道且最为知名的第四纪哺乳动物化石产地之一。此 地区出土的哺乳动物群经常被作为我国南方第四纪古生物年代对比的标准, 但该动物群的时代 却因确切地点不明、层位不清等原因而存在很大争议。本文依据最近的调查结果和新发现, 对这 一区域哺乳动物化石群的分布和时代状况等问题进行了探讨和解释. 新发现的大垭口裂隙动物 群含 Rhizomys troglodytes, Homotherium sp., Panthera pardus, Stegodon orientalis, Dicerorhinus sumatrensis, Hesperotherium sinense, Sus sp., Cervavitus fenqii, Cervus sp.和 Muntiacus sp.等, 其时 关键词 盐井沟 大垭口 更新世 哺乳动物群 生物地层 代为早更新世中期，证实了盐井沟地区存在早更新世的动物群。在否定“万县动物群”或“盐井沟 动物群”作为盐井沟地区更新世中晚期的生物地层学层位的同时, 建议将大垭口动物群和平坝上 洞动物群分别视为该地区早更新世中期和中更新世早期可资对比的生物地层学层位.

重庆市万州区盐井沟是中国南方第四纪哺乳动 物化石的经典产地, 以石灰岩裂隙(俗称“坚井”)中保 存的众多完整化石而闻名于世. 早在 1870 年, Owen ${ }^{[1]}$ 就研究了据称产自重庆府附近的动物化石, 并命名 了东方剑齿象(Stegodon orientalis)、中国犀(Rhinoceros sinensis)、中国貘(Tapirus sinensis) 等几个我国南方更 新世最常见的种类, 这些化石一度被认为出土于盐 井沟(虽然事实可能并非如此). 日本学者 Matsumoto ${ }^{[2]}$ 研究了可能产于盐井沟(原文中为出土于四川)的一 些第四纪哺乳动物化石, 但他的研究材料少且浅显. 20 世纪 20 年代, 美国中亚考察团成员的 Granger 首 次进入盐井沟地区，收集了大量化石运回美国，并发
表了初步的研究报告 ${ }^{[3]}$, 这是我国南方第一个确切的 第四纪哺乳动物群.

长久以来, 作为大熊猫-剑齿象动物群 (狭义)的 典型“地点”, 万州盐井沟动物群的年代问题一直困 扰着第四纪古生物学者. Matthew 和 Granger 的初步 研究报告 ${ }^{[3]}$ 一文中涉及到该动物群的时代, 由于受到 爪兽(Hesperotherium, 原文中为 Chalicotherium) 和剑 齿象(Stegodon)的影响, 即认为此两物种的地层层位 偏早, 故将其视为上新世; 尔后, Teilhard de Chardin 等人 ${ }^{[4]}$ 在讨论广西洞穴沉积物的时代时认为, 盐井沟 的动物群与我国南方洞穴的黄色堆积中的动物群同 时代，属于早更新世; Colbert ${ }^{[5]}$ 则认为中国南方洞穴 
的黄色堆积和盐井沟堆积为中更新世; 1953 年, Colbert 和 Hooijer ${ }^{[6]}$ 系统地研究了 Granger 采集的盐井沟 动物群, 这些材料包括 7 目 20 科 28 种, 概称“万县动 物群”或 “盐井沟动物群”, 从标本的石化程度判断这 些收集品是中更新世早期至现代连续积累的, 将其 主体时代定格在中更新世; 裴文中 ${ }^{[7]}$ 和周明镇 ${ }^{[8]}$ 等人 亦将其置于中更新世; Kahlke ${ }^{[9]}$ 人为地将之分为 $I$ 和 II 两组, I 组为中更新世早期, 含有较古老的类型, II 组为中更新世晚期; 李炎贤 ${ }^{[10]}$ 亦认可 Kahlke 的观 点, 但将 II 组认定为从中更新世晚期至整个晚更新 世; 郑绍华 ${ }^{[11]}$ 则将它们全部归人平坝上洞动物群之 中, 也就是中更新世早期. 造成这些不同意见的原因 在于 Granger 收集的化石非常复杂, 该动物群中的大 多数材料虽说是出自平坝, 但缺乏准确的出土地点 和层位, 而且还混杂了周边地区出土的各个时代的 化石种类, 部分标本石化程度很浅, 少数甚至还保存 着骨骼的弹性 ${ }^{[6]}$. 而且, 以往的古生物学者又往往以 这些脱离层位的混杂种类或者单一裂隙的动物化石 来讨论整个盐井沟地区动物群的时代.

为解决盐井沟地区动物化石的分布情况与时代 问题, 2010 2011 年, 重庆三峡古人类研究所组织力 量在这一地区进行了广泛的走访和调查, 并发掘了 数量可观的有确定地点和层位的化石标本.

\section{1 地质概况}

盐井沟隶属万县盐井乡 (现为万州区新田镇盐井
社区), 所在地为一条较为宽阔的山谷. 谷中有建国 后修建的新田水库, 库区内曾是出土化石的产区之 一, 但这一区域出土化石数量很少. 真正的盐井沟动 物群的产地其实并不在盐井沟内, 而是在盐井沟东 南侧的方斗山背斜之上、以平坝槽为代表的一系列北 东-南西走向的高海拔喀斯特槽谷之中. 图 1 示盐井 沟地区化石产地的分布区域和地貌景观. 平坝槽北 高南低, 海拔均在 $800 \mathrm{~m}$ 以上, 由一个个馒头状的石 灰岩溶蚀山丘(喀斯特峰丛)和山间溶蚀洼地构成, 山 顶为 “山原期夷平面”. 在夷平面之下的“馒头山”上和 槽谷之中发育着众多的喀斯特裂隙, 其形态各异, 有 深有浅, 盐井沟地区丰富的哺乳动物化石就埋藏在 这些裂隙的堆积物之中.

产化石裂隙的分布相当广泛, 自平坝槽沿北东南西走向可延续数十公里, 最北至方斗山的北界, 即 万州区油沙乡何家院子附近, 此处地貌由喀斯特峰 丛演变为单斜山; 最南端界限不明, 因为由北向南, 喀斯特峰丛逐渐变得低矮, 产化石裂隙也随之逐渐 减少, 但至少在石柱县河嘴乡旗峰村亦有分布. 在 Granger ${ }^{[12]}$ 的考察报告里也曾提到, 从盐井沟沿着含 化石的裂隙山梁(Dragon Bone Ridge)至四五十英里 远的地方还有化石可寻. 在何家院子一位九十开外 的老人讲, 他的长辈曾在附近的坚井(裂隙)中挖掘出 一具单独的完整牛骨架, 并卖给了美国人, 我们推测 这具牛骨架很有可能就是 Colbert 和 Hooijer ${ }^{[6]}$ 所提到 的 Bibos gaurus grangeri (AMNH 18465). 由此亦可

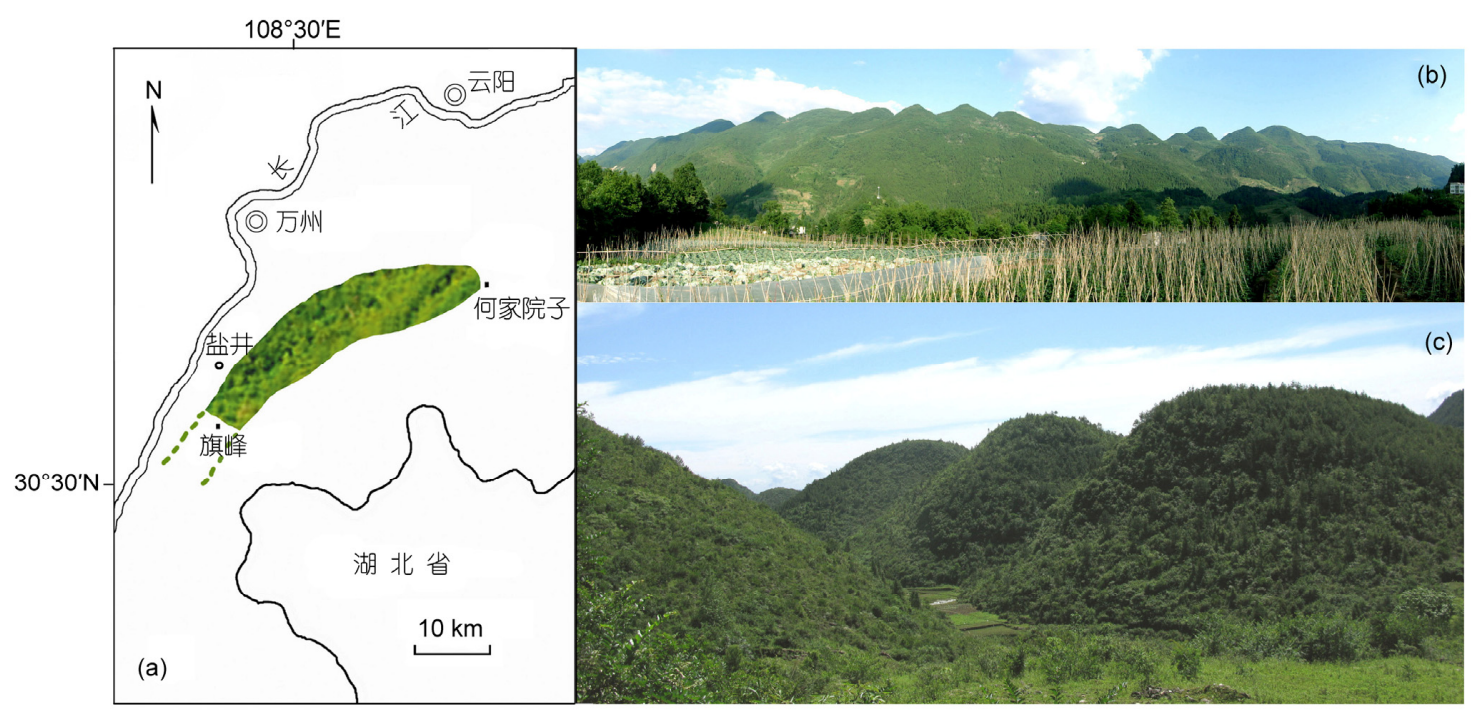

图 1 盐井沟地区的化石分布区域及当地地貌景观

(a) 化石地点分布区域(绿色部分); (b) 方斗山地貌(自盐井沟下观看); (c) 平坝槽内的溶蚀山丘 
佐证, Granger 收集的化石来自众多地点, 并非同一 层位、同一时代.

\section{2 哺乳动物化石}

自 Matthew 和 Granger ${ }^{[3]}$ 发表初步研究报告以后, 盐井沟的哺乳动物化石便受到世人的关注. Young 等 人 $^{[13,14]}$ 于 1934 年和 1936 年先后到访此地, 并采集了 少量的化石标本. 但之后便无专业古生物学者前往 此地, 直到 1984 1986 年, 郑绍华 ${ }^{[1]}$ 等人组成的调查 队才又进人平坝槽进行了为数不多的古生物学调查 和发掘工作. 从已发表的资料来看, 盐井沟地区动物 群的种类非常丰富, 至少包括 8 目 46 种. 我们在调查 的同时, 也进行了一系列的化石标本采集工作, 其中 以大垭口地点第二层出土的化石最有代表性.

大垭口地点为一垂直裂隙, 发育在三叠纪嘉陵江 灰岩构成的南东-北西走向的山坡之上, 裂隙顶端距坡 底高差约 $10 \mathrm{~m}$, 地理坐标: $30^{\circ} 37^{\prime} 37.1^{\prime \prime} \mathrm{N}, 108^{\circ} 26^{\prime} 56.9^{\prime \prime} \mathrm{E}$, 海拔高度为 $910 \mathrm{~m}$. 裂隙口近圆形, 直径约 $5 \mathrm{~m}$, 其 内堆积物主要为角砾岩, 依其岩性与产状, 自上而下 可划分为 3 层(图 2):

(1) 棕红色黏土层. 底部含中国犀和水牛等化石. 此层因当地农民挖水井而有局部扰动. 厚度不等.

$$
<1.5 \mathrm{~m}
$$

（2）灰色角砾层. 角砾以灰岩为主，棱角分明，中 等大小, 砾径从 $5 \mathrm{~cm}$ 至 $20 \mathrm{~cm}$ 不等, 以 $8 \sim 15 \mathrm{~cm}$ 者较多, 角砾间填充物为棕黄色粉砂质黏土, 黏土间还夹有钟乳 石断块和多层钙质胶结的碳酸盐类沉积物. 绝大多数化
石埋藏于此层.

$\sim 2.5 \mathrm{~m}$

(3) 灰黑色巨砾层. 成分为石灰岩角砾, 砾径超过 $1 \mathrm{~m}$, 呈板状分布, 未见底.

$>1 \mathrm{~m}$

\section{1 大症口哺乳动物化石}

大垭口化石地点第二层的哺乳动物化石包含有 5 目 8 科 12 种, 计有: 咬洞竹鼠 Rhizomys troglodytes Matthew et Granger, 1923、鼠科属种未定 Muridae gen. et sp. indet. 似剑齿虎未定种 Homotherium sp、、豹 Panthera pardus Linnaeus, 1875、猫科属种未定 Felidae gen. et sp. indet. 东方剑齿象 Stegodon orientalis Owen，1870、苏门答腊犀 Dicerorhinus sumatrensis Fischer, 1814、中华黄昏爪兽 Hesperotherium sinense (Owen, 1870)、猪(未定种)Sus sp.、凤岐祖鹿 Cervavitus fenqii Han, 1987、鹿(未定种) Cervus sp. 和 麇(未定种)Muntiacus sp.

\section{2 主要种类简述}

咬洞竹鼠 Rhizomys troglodytes: 咬洞竹鼠的材 料在盐井沟地区非常丰富, 但此地点的竹鼠类数量 不多, 仅以数件下领骨和零散上白齿为代表. 下领骨 咬肌脊下支较上支粗壮，二者前端交汇处呈锐角，与 $\mathrm{m} 1$ 前缘大致处于同一垂直线上; 㬵孔很小, 位于咬 肌脊交汇处的前下方; 齿隙长 $9.6 \mathrm{~mm}$, 下臼齿列齿 槽长 14.5 15.5 mm, m1 处下领骨高度在 $13.5 \mathrm{~mm}$ 左 右. 与盐井沟地区出土的 Rhizomys sinensis 相比, 仅 在嫆孔的大小和位置上有所差异.

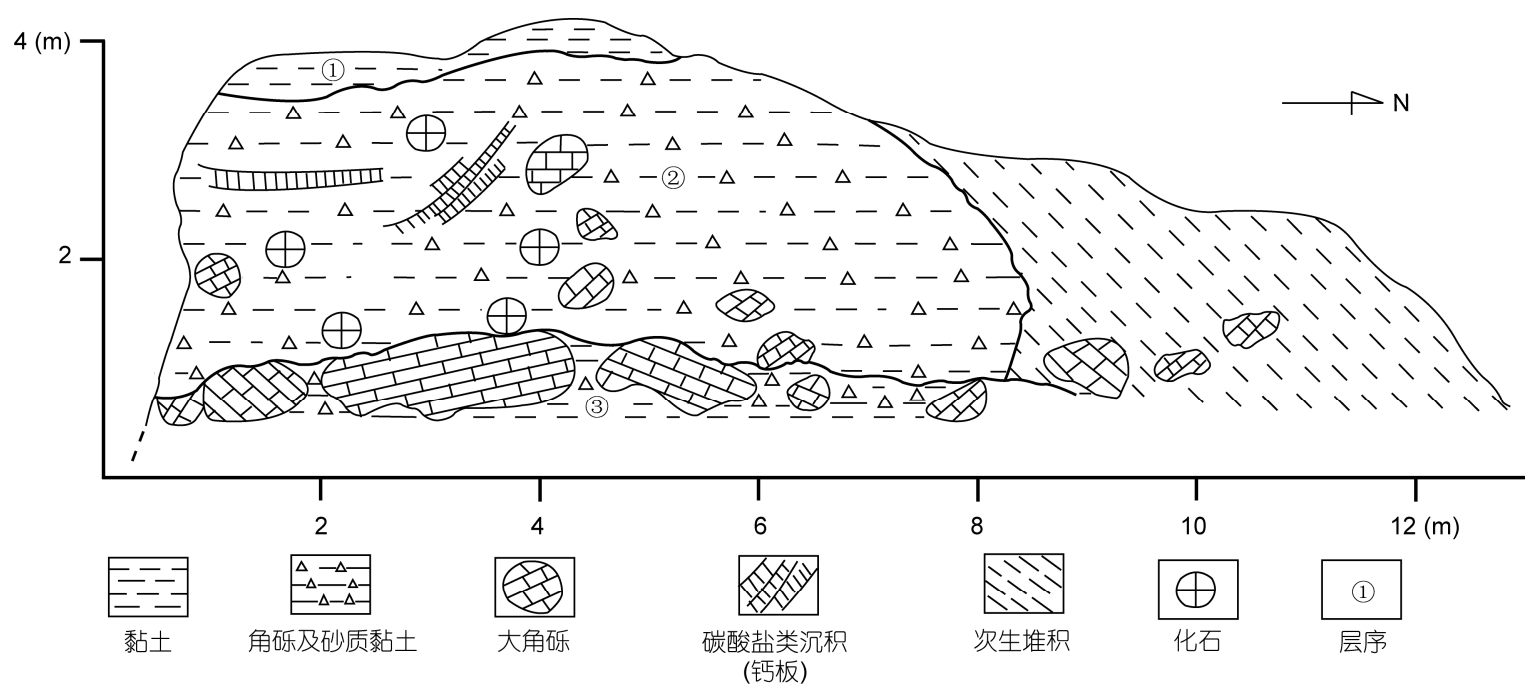

图 2 大垭口地点地层剖面图 
似剑齿虎(未定种) Homotherium sp.: 剑齿虎类 仅有 1 枚破损的上犬齿(图 3A) 和 1 枚上门齿, 其上犬 齿较薄, 弯曲度小, 前、后刃缘均具锯齿, 依此特征, 可以鉴定为 Homotherium. 但在大垭口出土的这类化 石数量少, 不能作进一步研究, 仅证明在此地点有 Homotherium 的存在.

豹 Panthera pardus: 材料以 1 件残破上领骨(图 $3 \mathrm{~B}) 、 1$ 件 $\mathrm{m} 1$ 和数件肢骨为代表. P 3 前附尖极不发育, 位于舌侧; 主尖强壮, 位于中间稍靠后的位置; 后附 尖中等发育，与后齿带的联系不紧密; 前齿带弱, 后 齿带发育稍呈棚架状. P4 原尖呈小的圆雉状, 位低, 位于前附尖和前尖中间水平; 前附尖较原尖大, 前唇 侧无附加小尖; 前尖高等; 后附尖呈近水平延伸的 切割叶, 与前尖长度相当; 齿带仅在前附尖前唇侧有 弱的发育. P3 长 $19.5 \mathrm{~mm}$, 宽 $10.5 \mathrm{~mm}$; P4长 $29.3 \mathrm{~mm}$, 宽 $15.5 \mathrm{~mm}$.
东方剑齿象 Stegodon orientalis: 材料包括完整 程度不等的 3 具骨架和十余枚零散顿齿 (图 3C D). 从保存完整的 M3 来看, 其齿冠低, 冠面次长方形, 前窄后宽，由 9 个齿脊和前齿带、后跟座组成. 牙齿 长 $235 \mathrm{~mm}$ 左右, 第一齿脊宽 90 95 mm, 第四齿脊宽 92 95 mm. 第九齿脊宽 52 54 mm. 齿脊频率 3.3. 釉 质厚度 $5 \mathrm{~mm}$ 左右, 禇皱弱. 第一齿脊中等磨蚀, 第 二齿脊稍有磨蚀, 其他齿脊未磨蚀. 齿谷宽阔, 呈 $\mathrm{V}$ 字型，谷内白严质中等发育. 各齿脊间的齿谷谷底 舌、唇侧均无齿柱. 第一齿脊具有明显的中沟, 将此 齿脊分为内外两部分, 外侧由 3 个齿柱构成, 磨蚀后 形成 3 个未完全分离的釉质环，内侧为脊状，磨蚀后 具有部分乳齿象的性质，即三叶型构造. 第二齿脊明 显处于由脊状向乳突状过渡的阶段, 其上的乳突尚 未分离, 中沟亦显著发育. 第三至第六齿脊中部向后 弯曲. 第七至第九齿脊依次变窄, 乳突数量也依次减

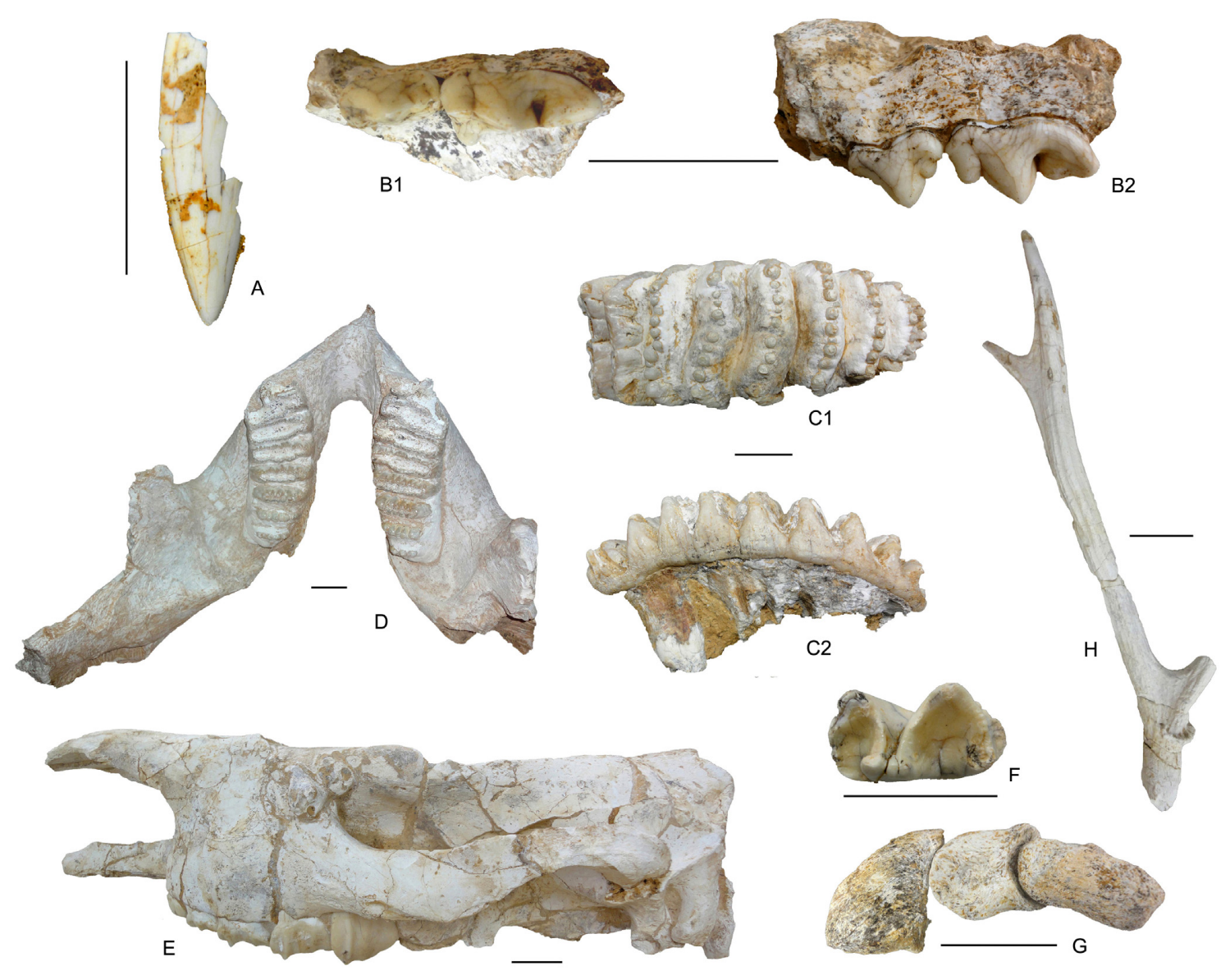

图 3 大垭口地点发现的部分哺乳动物化石

$\mathrm{A}$, 似剑齿虎(未定种)右犬齿, 舌侧视. B, 豹上领骨; B1, 冠面视; B2, 舌侧视. C, 东方剑齿象左 M3; C1, 冠面视; C2, 舌侧视. D, 东方剑齿象下领 骨, 冠面视. E, 苏门答腊犀头骨, 侧面视. F, 中华黄昏爪兽右 $\mathrm{m} 1$, 冠面视. $\mathrm{G}$, 中华黄昏爪兽趾骨, 侧面视. H, 凤歧祖鹿左角, 侧面视. 比例尺: $4 \mathrm{~cm}$ 
少. 构成第三至第九齿脊的乳突均较大, 乳突数量在 7 11 个之间. 前齿带和后跟座由乳突构成.

苏门答腊犀 Dicerorhinus sumatrensis: 大垭口地 点第二层采集的化石包括 1 件较为完整的幼年头骨 (图 3E) 及部分头后骨骼. 这件幼年头骨顶面近平直; 角瘤尚不明显, 鼻骨前端向下倾斜, 末端尖细, 腹面 凹陷, 顶面粗糙; 额骨扁平. 从头骨的形态来看, 其 明显属于苏门犀(D. sumatrensis). 上、下领各有一对 乳门齿发育, DP1 和 $\mathrm{dp} 1$ 均存在.

中华黄昏爪兽 Hesperotherium sinense: 是一种 非常稀少的已灭绝了的奇蹄类, 在大垭口地点的数 量相对较多, 包括 2 枚上前臼齿、3 枚下臼齿和数件 趾骨(图 $3 F$ 和 G). 爪兽的最奇特之处在于它们不具有 其他有蹄类动物的蹄，而代之以特化的中间分裂的 爪. 大垭口地点 Hesperotherium 的趾骨是继河北阳原 泥河湾 ${ }^{[15]}$ 和安徽繁昌人字洞 ${ }^{[16]}$ 后的第三次发现, 且 数量居首.

凤岐祖鹿 Cervavitus fenqii: 仅有 1 件保存基本 完整的左侧鹿角(图 $3 \mathrm{H}$ ), 在出土时眉枝的端部破损. 典型的三枝角; 中等大小. 角的表面较光滑, 具浅的 纵向沟和棱; 角柄短, 横切面近圆形, 横径 $29.2 \mathrm{~mm}$; 角环向前内侧倾斜, 在角的前部明显发育, 而在后侧 则非常弱; 主枝直, 与角柄的夹角约在 $150^{\circ}$ 左右, 下 部横切面近圆形, 向上则逐渐变为椭圆形; 眉枝短且 直, 与主枝的夹角约为 $50^{\circ}$; 第二枝较眉枝更细更短, 与主枝的夹角约为 $60^{\circ}$; 末枝略有弧度, 表面光滑.

\section{3 时代判断}

大垭口地点的 Hesperotherium 和 Cervavitus 是新 近纪的子遗属, Hesperotherium 目前已知的最晚记录 是陕西蓝田公王岭 ${ }^{[17]}$, Cervavitus fenqii 仅见于早更 新世早-中期的广西柳城巨猿洞 ${ }^{[18]}$ 、么会洞和三合大 洞 ${ }^{[19]}$ 、重庆巫山龙骨坡和湖北建始龙骨洞 ${ }^{[20]}$ 和安徽 繁昌人字洞 ${ }^{[21]}$. Homotherium 在我国南方已知的可靠

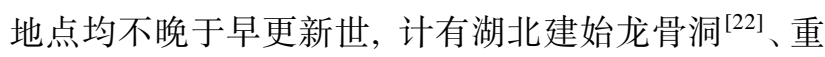
庆巫山龙骨坡 ${ }^{[23]}$ 、安徽繁昌人字洞 ${ }^{[24]}$ 、四川德格汪 布顶 ${ }^{[25]}$ 、江苏溧阳 ${ }^{[26]}$ 及湖北郧县人地点 ${ }^{[27]}$. Rhizomys troglodytes 最早见于巫山龙骨坡的裂隙堆积, 其时代 为早更新世早期或中期; 最晚则出现在盐井沟地区, 即所谓的“盐井沟 I 期”, 为中更新世早期. Stegodon orientalis 属于中-晚更新世的常见种类, 大垭口地点 的剑齿象化石虽然鉴定为 S. orientalis, 但它的 M3 却
有一些相对于晚期同类较原始而对于早期 S. huananensis 更进步的特征，例如: (1) 牙齿由 9 个齿脊和前 齿带、后跟座组成，晚期 S. orientalis 的 M3 由 10 11 个齿脊和一个跟座组成, S. huananensis 的 M3 则由 7 8 个齿脊构成; (2) 构成齿脊的乳突较大, 乳突数 在 7 11 个之间, 晚期 S. orientalis 的乳突个体很小, 数量一般大于 10 个, S. huananensis 的乳突大者多、小 者少，数量一般小于 10 个; (3) 中沟在前两个齿脊明 显存在, 第三、四齿脊上也能看到中沟的痕迹, $S$. huananensis 正型标本和晚期 S. orientalis 的中沟仅见 于第一齿脊; (4) 第一、二齿脊也显示了较晚期 $S$. orientalis 更为原始的特征. Panthera pardus 和 Dicerorhinus sumatrensis 的生存历史贯穿整个更新 $世^{[23,28]}$, 在年代分析上没有太大的意义.

由绝灭属的比例(4 个, 占可鉴定属的 $40 \%$ )、动 物群组成和 Stegodon orientalis 的进化水平来看, 将 大垭口动物群的年代鉴定为早更新世早期或中期是 比较恰当的. 金昌柱等人 ${ }^{[29]}$ 曾对我国南方早更新世 的动物群年代做过厘定, 早更新世早期化石群有广 西柳城巨猿洞动物群和重庆巫山龙骨坡动物群, 早 更新世中期的化石群有湖北建始龙骨洞动物群、广西 柳州笔架山动物群、云南元谋人动物群和云南迪庆香 格里拉(中甸)动物群. 图 4 示大垭口动物群各成员的 地史分布及与其相关动物群组成的比较. 可见在大 垭口动物群中, 鉴定到种或属一级的物种, 除 Dicerorhinus sumatrensis 外, 在建始龙骨洞全部存在 (建始龙骨洞与大垭口地点的 Stegodon 可能属于同类, 而非原鉴定的 S. cf. S. preorientalis), 这两个地点动 物群的相似程度最高. 有鉴于此, 我们把大垭口地点 动物群的时代暂视为早更新世中期, 与湖北建始龙 骨洞的层位相当.

\section{3 盐井沟哺乳动物化石的时代}

在 20 世纪, 盐井沟的哺乳动物群主要是由 Granger 收集的 “万县动物群” ${ }^{[3]}$ 及中国科学院古脊椎 动物与古人类研究所和重庆自然博物馆联合发掘的 平坝上洞动物群和平坝下洞动物群 ${ }^{[1]}$ 所构成. 这些 动物群的化石数量和种类都很丰富, 但是对其时代 的解读都比较含蓄. 造成这一局面的最核心因素就 是 Granger 收集的化石不仅出土地点不详, 而且无层 位记录; 至于郑绍华 ${ }^{[11]}$ 提到 Granger 采集的化石主要 出自山王庙裂隙, 其依据非当时的文录, 而是靠走访 


\begin{tabular}{|c|c|c|c|c|c|c|c|c|c|c|}
\hline \multirow[b]{2}{*}{ 大垭 $\square$} & \multicolumn{4}{|c|}{ 地质时代 } & \multicolumn{6}{|c|}{ 与相关动物群的对比 } \\
\hline & Q1 & Q2 & Q3 & Q4 & GC & LGP & LGC & BJS & YM & ZD \\
\hline \multirow{4}{*}{$\begin{array}{l}\text { Rhizomys troglodytes } \\
\text { Homotherium sp. } \\
\text { Panthera pardus } \\
\text { Stegodon orientalis }\end{array}$} & & & & & \multirow[b]{3}{*}{+} & + & \multicolumn{2}{|l|}{+} & \multirow[t]{2}{*}{-} & \\
\hline & & & & & & - & \multicolumn{2}{|l|}{+} & & \\
\hline & & & & & & + & + & & + & \\
\hline & & & & & - & 一 & \multirow[t]{2}{*}{$+*$} & \multirow[t]{2}{*}{+} & \multirow[t]{2}{*}{ - } & \\
\hline \multirow{2}{*}{$\begin{array}{l}\text { Dicerorhinus sumatrensis } \\
\text { Hesperotherium sinense }\end{array}$} & & & & & + & & & & & \\
\hline & & & & & + & + & \multirow{2}{*}{$\begin{array}{l}+ \\
+\end{array}$} & & + & \\
\hline \multirow{4}{*}{$\begin{array}{l}\text { Sus sp. } \\
\text { Cervavitus fenqii } \\
\text { Cervus sp. } \\
\text { Muntiacus sp. }\end{array}$} & & & & & \multirow{4}{*}{$\begin{array}{l}+ \\
+ \\
+ \\
+\end{array}$} & + & & + & + & \\
\hline & & & & & & + & + & & - & - \\
\hline & & & & & & + & + & + & + & - \\
\hline & & & & & & + & + & + & + & + \\
\hline
\end{tabular}

图 4 大垭口动物群各成员的地史分布及与其相关动物群组成的比较

$\mathrm{GC}$, 巨猿洞动物群; LGP, 龙骨坡动物群; LGC, 龙骨洞动物群; BJS, 笔架山动物群; YM, 元谋人动物群; $\mathrm{ZD}$, 香格里拉(中甸)动物群. +, 同种; 一, 同属不同种; *, 原鉴定为不同种

当地老农的回顾. 另外, 用化石的石化程度来判断其 年代的早与晚, 也是不可靠的，因为洞穴或裂隙的特 殊堆积类型有时会误导不太熟悉情况的学者, 在某 些情况下，动物骨骼由于被周围的沉积物所封闭，而 很难石化. 总之, 仅依靠文献分析、标本石化程度或 者老农回顾等等试图对盐井沟地区动物群进行准确 的年代判定几乎是不可能的. 唯一的办法是寻找新 地点, 系统、科学的发掘, 并将化石在地层里的三维 状态记录下来加以综合研究.

近些年来, 随着盐井沟地区的广泛调查和大垭口 地点的新发现, 使我们有机会能够更好地重新诠释这 一经典地区的哺乳动物群的时代内涵. 诚然, 我们在 盐井沟的调查、发掘和研究工作刚刚起步, 对这里的 裂隙堆积了解甚少, 采集的化石也十分有限. 但是, 有了大垭口这个新的化石地点, 结合前人的研究工作 成果，可以对盐井沟动物群的时代问题作出如下解读:

（i ）早更新世. 盐井沟地区, 目前能够确定为 早更新世地点及其动物组合仅此一处，这就是本文 记述的大垭口地点. 该地点的动物组合面貌是以 Homotherium sp., Hesperotherium sinense, Cervavitus fenqii, Rhizomys troglodytes 以及较原始的 Stegodon orientalis 为代表, 其特点是绝灭属比例高, 新近纪残 留种类多, 现生种类少(仅有 Dicerorhinus sumatrensis 和 Panthera pardus 两个可鉴定种). 另外, 原“万县 动物群”中的爪兽类标本 ${ }^{[6]}$ 与大垭口 Hesperotherium sinense 的性质十分相近, 也就是说, Granger 收集品 中的爪兽层位应该与大垭口的爪兽一致，亦属早更 新世. 这同时也提示 Granger 收集品中可能还有少量 其他早更新世的标本. (ii) 中更新世. 盐井沟地区的中更新世地点, 可能数量很多, 但目前可以确定并且层位清楚的, 仅 有平坝上洞，该动物群由郑绍华等人于 20 世纪 80 年 代发掘、研究. 出土化石较多, 但仅有啮齿类研究发 表, 其中绝灭种少，仅有 Rhizomys troglodytes 和巫山 攀鼠 (Vernaya wushanica $)^{[11]}$. 另外, 其他种类依郑绍 华 ${ }^{[11]}$ 报道，有食虫类、翼手类、兔形类、灵长类 (2 种)、长鼻类(1 种, Stegodon orientalis)、肉食类(6 种, 含 Ailuropoda melanoleuca baconi)、奇蹄类(1 种, Megatapirus augustus)及偶蹄类(7 9 种), 平坝上洞的 大哺乳种类并未超出 “万县动物群”的范围, 且缺少 其重要成员 Hesperotherium 和 Rhinoceros sinensis. 郑绍华 ${ }^{[11]}$ 依据小哺乳类组合, 认为平坝上洞动物群 晚于天桥期而早于歌乐山期，这显然是非常合理的， 但问题在于他将 Granger 收集品也纳人平坝上洞动物 群, 并依据 Hesperotherium 和陕西蓝田公王岭动物群 相对比, 这似乎是不太妥当的. 因为 Granger 收集品 是多个地点与时代动物种类的集合, 不能纳人任何 单一地点、时代的动物群. 平坝上洞动物群的时代应 当是中更新世的早期.

（iii）晚更新世. 盐井沟地区晚更新世地点以水 平溶洞较多, 垂直裂隙相对较少. 垂直裂隙目前仅有 郑绍华发掘的平坝下洞 ${ }^{[11]}$. 在我们调查的地点中, 以媒人洞 $\left(30^{\circ} 35^{\prime} 49.7^{\prime \prime} \mathrm{N}, 108^{\circ} 25^{\prime} 47.5^{\prime \prime} \mathrm{E}\right.$, 海拔高度为 $913 \mathrm{~m})$ 这一水平溶洞出土的化石种类最为丰富, 成 分属性与典型的大熊猫-剑齿象动物群相当，例如 Macaca sp., Rhizomys sinensis, Hystrix subcristata, Canis sp., Ursus thibetanus, Ailuropoda melanoleuca baconi, Arctonyx collaris, Crocuta ultima, Stegodon 
orientalis, Megatapirus augustus, Rhinoceros sinensis, Sus scrofa, Rusa unicolor, Bubalus bubalis 和 Bibos gaurus 等. 另外, 此地点的啮齿类与平坝下洞动物 群一致, 均为现生种类, 推测其年代为晚更新世 晚期.

\section{4 小结}

通过 2010 2011 年在盐井沟地区的调查与标本 采集工作, 对此喀斯特地区哺乳动物化石的埋藏与 分布、层位与时代等状况有了初步的清晰认识. 盐井 沟地区第四纪哺乳动物化石群主要分布在方斗山背
斜之上的一系列北东-南西走向的喀斯特槽谷之中, 产化石裂隙可沿这些槽谷延续数十公里.

新发现的大垭口哺乳动物群因含有较多的新近 纪子遗属, 而被鉴定为早更新世中期. 在证实盐井沟 地区存在早更新世动物群的同时, 通过实地调查、走 访, 认识到 Granger 的绝大多数收集品确实存在地点 不明、层位不清等诸多问题。为此，我们建议取消“万 县动物群”或“盐井沟动物群”作为盐井沟地区更新世 中晚期的生物地层学层位, 而将大垭口动物群和平 坝上洞动物群分别视为盐井沟地区早更新世中期和 中更新世早期可资对比的生物地层学层位.

Matsumoto H. On some fossil mammals from Sze-chuan, China. Sci Rep Tohoku Imp Univ, Ser 2 (Geol), 1915, 3: 1-28

3 Matthew W D, Granger W. New fossil mammals from the Pliocene of Szechuan, China. Bull Am Mus Nat Hist, 1923, 48: 563-598

4 Teilhard de Chardin P, Young C C, Pei W C, et al. On the Cenozoic formations of Kwangsi and Kwangtung. Bull Geol Soc China, 1934, 13: 179-205

5 Colbert E H. Pleistocene mammals from the Ma Kai Valley of Northern Yunnan, China. Am Mus Nov, 1940, 1099: 1-10

6 Colbert E H, Hooijer D A. Pleistocene mammals from the limestone fissures of Szechuan, China. Bull Am Mus Nat Hist, 1953, 102: 1-134

7 裴文中. 中国第四纪哺乳动物群的地理分布. 古脊椎动物学报, 1957, 1: 9-24

8 周明镇. 华南第三纪和第四纪初期哺乳动物群的性质和对比. 科学通报, 1957, 13: 394-400

9 Kahlke H D. 关于中国南方剑齿象-熊猫动物群和巨猿的时代. 古脊椎动物与古人类, 1961, 2: 83-108

10 李炎贤. 我国南方第四纪哺乳动物群的划分和演变. 古脊椎动物与古人类, 1981, 19: 67-76

11 郑绍华. 川黔地区第四纪啮齿类. 北京: 科学出版社, 1993. 270

12 Granger W. Palaeontological exploration in eastern Szechwan. In: Andrews R C, ed. The New Conquest of Central Asia. Natural History of Central Asia, Vol. 1. New York: the American Museum of Natural History, 1932. 501-528

13 Young C C. Note on a mammalian microfauna from Yenchingkou near Wanhsien, Szechuan. Bull Geol Soc China, 1935, 14: 247-248

14 Young C C. New fossils from Wanhsien (Szechuan). Bull Geol Soc China, 1939, 19: 317-332

15 Teilhard de Chardin P, Piveteau J. Les mammifères fossiles de Nihowan (Chine). Ann Paleont, 1930, 19: 1-134

16 同号文, 邱占祥. 奇蹄目. 见: 金昌柱, 刘金毅, 编. 安徽繁昌人字洞——早期人类活动遗址. 北京: 科学出版社, 2009. 286-320

17 胡长康, 齐陶. 陕西蓝田公王岭更新世哺乳动物群. 中国古生物志, 1978, 新丙种(21): 1-64

18 韩德芬. 广西柳城巨猿洞偶蹄目化石. 中国科学院古脊椎动物与古人类研究所集刊, 1978, 18: 135-208

19 Dong W. Reconsideration of the systematics of the Early Pleistocene Cervavitus (Cervidae, Artiodactyla, Mammalia). Estudios Geologicos, 2011, 67: 603-611

20 陈冠芳. 偶蹄目. 见: 郑绍华, 编. 建始人遗址. 北京: 科学出版社, 2004. 254-308

21 董为, 邱占祥, 汪发志. 偶蹄目. 见: 金昌柱, 刘金毅, 编. 安徽繁昌人字洞一一早期人类活动遗址. 北京: 科学出版社, 2009. 321-335

22 张兆群, 冯小波. 见: 郑绍华, 编. 建始人遗址. 北京: 科学出版社, 2004. 185-220

23 黄万波, 方其仁. 巫山猿人遗址. 北京: 海洋出版社, 1991. 230

24 刘金毅, 邱占祥. 食肉目. 见: 金昌柱, 刘金毅, 编. 安徽繁昌人字洞一一早期人类活动遗址. 北京: 科学出版社, 2009. 220-282

25 宗冠福, 陈万勇, 黄学诗, 等. 横断山地区新生代哺乳动物及其生活环境. 北京: 海洋出版社, 1996.279

26 雷次玉, 林一璞. 江苏溧阳夏林似剑齿虎一新种. 古脊椎动物与古人类, 1982, 20: 54-58

27 Echassoux A, Moigne A M, Moullé P É, et al. Les faunes de grands mammifères du site de l'Homme de Yunxian. In: De Lumley H, Li T Y, eds. Le Site de 1'Homme de Yunxian. Paris: CNRS Édition, 2008. 253-364

28 Tong H W. Evolution of the non-Coelodonta dicerorhine lineage in China. C R Palevol, 2012, 11: 555-562

29 金昌柱, 郑家坚, 王元, 等. 中国南方早更新世主要哺乳动物群层序对比和动物地理. 人类学学报, 2008, 27: 304-317 